\title{
Increased mucosal damage during parasite infection in mice fed an elemental diet
}

\author{
ANNE FERGUSON, R F A LOGAN, AND T T MACDONALD ${ }^{1}$ \\ From the Gastro-Intestinal Unit, University of Edinburgh, and Western General Hospital, Edinburgh
}

SUMMARY We have examined the effects of parasite infection on the mucosal architecture of mice maintained on an elemental diet (Vivonex). Techniques used were conventional histology, microdissection and measurement of individual villi and crypts, and measurement of crypt cell proliferation rate by a metaphase accumulation technique. In normal, non-parasitised mice the elemental diet caused no change in villus height, crypt depth, or crypt cell proliferation. Likewise, the only effects of chronic protozoal infection or Nippostrongylus brasiliensis infection on the intestine of mice fed a normal diet have been a slight crypt hypertrophy and an increase in crypt cell proliferation rate without villous atrophy. However, the combination of elemental diet and parasite infection resulted in increased mucosal damage when compared with infected mice on a normal diet. Elemental diet mice infected with the nematode Nippostrongylus brasiliensis had significantly reduced villus height and correspondingly raised crypt length and metaphase accumulation rate. Elemental diet mice infected with the protozoan Giardia muris did not have villous atrophy but there was a significant increase in crypt length and metaphase accumulation when compared with infected normal diet mice. These experiments show that in two animal models of enteric infection, elemental diet has altered the host parasite relationship to the detriment of the host.

Elemental diets are widely used in gastrointestinal practice. However, although their nutritional properties have been extensively evaluated, there is limited information available on the effects of this radical alteration in diet on intestinal physiology, microbiology, and immunology. We have reported that when mice were reared on an elemental diet and infected at the age of 3 months with the parasite Nippostrongylus brasiliensis, they became lethargic, wasted, and some died (Ferguson, 1976; Ferguson et al., 1978). Infection of rats with this nematode parasite results in changes in intestinal histopathology, with short villi, long crypts, and acceleration of epithelial cell turnover (Symons, 1965; Loehry and Creamer, 1969; Ferguson and Jarrett, 1975). The adverse clinical effects of elemental diet in infected mice would be in keeping with the presence of a more severe degree of malabsorption and enteropathy than usual. We have, therefore, examined further the effects of combined elemental diet and parasite infection in mice, by using a range of techniques to study mucosal damage-morphometry of villi and crypts, together with studies on crypt cell prolifera-

Received for publication 13 July 1979

'Present address: Thomas Jefferson University, Philadelphia. tion. Two parasites have been examined, the nematode Nippostrongylus brasiliensis and the protozoan Giardia muris.

\section{Methods}

ANIMALS

Two strains of mice were used-CBA (healthy and free of parasites) and Sha Sha (a strain known to be chronically infected with the protozoa Giardia muris and Hexamita muris) (MacDonald and Ferguson, 1978). At the time these experiments were conducted the principal organism in the Sha Shas was Giardia.

\section{Nippostrongylus brasiliensis INFECTION}

CBA mice were infected by a subcutaneous injection of $1000 \mathrm{~N}$. brasiliensis larvae (from a culture maintained at the Wellcome Laboratories of Experimental Parasitology, Glasgow). Culture of larvae and intestinal worm counts were performed by standard techniques (Jennings et al., 1963; Jarrett and Urquhart, 1968).

\section{DIETS}

The animals on a normal diet had free access to a standard mouse pellet feed, FFG(M), which is based 
on wheat, barley, maize, soya bean meal, white fish meal, and molasses.

Elemental diet animals had free access to Vivonex (Eaton Laboratories) rendered solid by incorporation in agar as follows. The contents of one packet, $80 \mathrm{~g}$, were dissolved in $100 \mathrm{ml}$ tepid water and mixed with $100 \mathrm{ml} 5 \%$ agar which had previously been dissolved by boiling and then cooled to around $60^{\circ} \mathrm{C}$. The two were mixed together using an egg whisk and allowed to solidify. Thereafter the solidified Vivonex was stored at $4^{\circ} \mathrm{C}$. The mice were weaned directly onto the elemental diet after separation from the mother 16 days after birth.

\section{POST-MORTEM EXAMINATION AND}

CONVENTIONAL HISTOPATHOLOGY

Animals were anaesthetised, the abdomen opened and small intestine taken from around $10 \mathrm{~cm}$ from the pylorus, for histopathological examination. This level of intestine was selected because it is the site of maximum concentration both of Nippostrongylus brasiliensis worms and of Giardia muris protozoa. Specimens were wax embedded and routinely cut and stained with haematoxylin and eosin.

For the study of liver weights and histology, individual mice were weighed, anaesthetised, the abdomen opened, the liver dissected out and immediately weighed. A piece of liver was then fixed in formol saline, wax embedded, routinely processed and stained with haematoxylin and eosin. Another piece of liver was snap frozen, and frozen sections were stained with Sudan IV.

MEASUREMENTS OF INTESTINAL ARCHITECTURE AND OF CRYPT CELL PRODUCTION

Groups of experimental animals were given intraperitoneal colchicine at a dose of $5 \mathrm{mg} / \mathrm{kg}$ body weight, and were killed at measured time intervals from one to two hours later. From each animal a segment of jejunum $10 \mathrm{~cm}$ from the pylorus was taken and fixed in $75 \%$ absolute alcohol, $25 \%$ acetic acid mixture. The tissue was then stained in bulk by the Feulgen reaction.

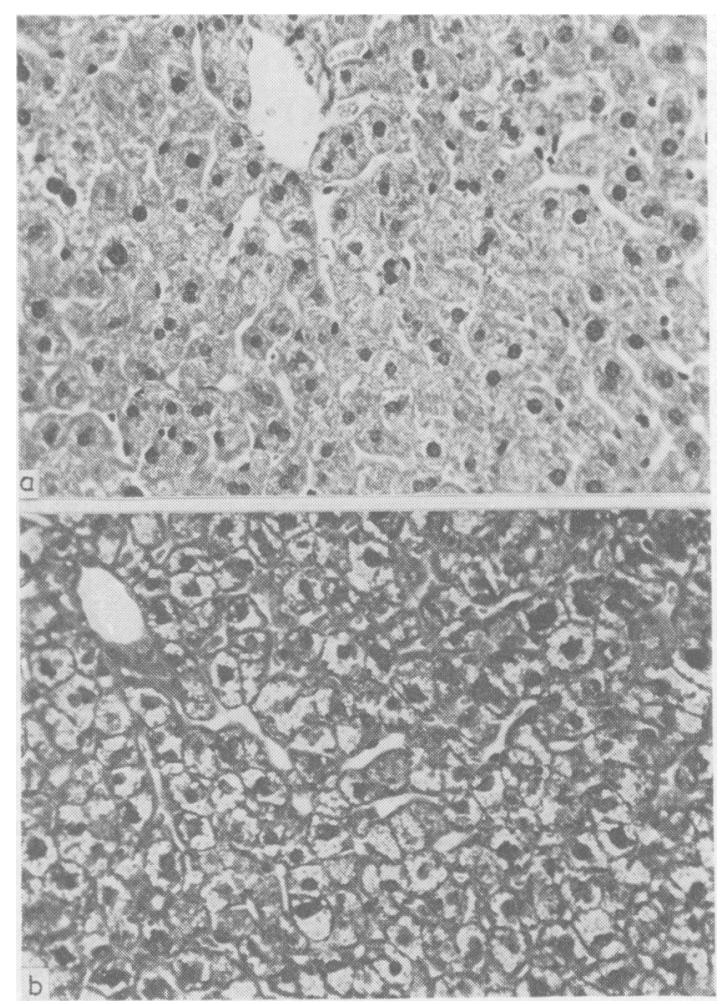

Fig. 1 Liver histology in a CBA mouse aged 10 weeks reared $(a)$ on a normal diet, $(b)$ on an elemental diet. $H$ and $E \times 320$ (original magnification).

With a dissecting microscope, and by using fine forceps and a cataract knife, single villi with associated crypts were cut free from the edge of the specimen, placed on a slide in a drop of $45 \%$ acetic acid, and a coverslip was applied gently. By using an eyepiece graticule and a light microscope the lengths of 10 villi and 10 crypts per specimen were measured. The preparation was then gently squashed by light pressure on the coverslip. This liberates the crypts from the lamina propria matrix and flattens them out. The number of metaphases were then counted

Table 1 Effects of elemental diet (Vivonex) on mouse liver

\begin{tabular}{|c|c|c|c|c|c|c|c|c|}
\hline \multirow[t]{2}{*}{$\begin{array}{l}\text { Experimental } \\
\text { group }\end{array}$} & \multirow[t]{2}{*}{$\begin{array}{l}\text { Number of } \\
\text { animals }\end{array}$} & \multicolumn{3}{|c|}{$\begin{array}{l}\text { Weight of mouse } \\
(\mathrm{g})\end{array}$} & \multicolumn{3}{|c|}{$\begin{array}{l}\text { Weight of liver } \\
(\mathrm{g})\end{array}$} & \multirow[t]{2}{*}{ Liver histology } \\
\hline & & Mean & $S E$ & $\mathbf{P}^{*}$ & Mean & $S E$ & $\mathbf{P}^{*}$ & \\
\hline Elemental diet & 6 & $19 \cdot 4$ & $0 \cdot 3$ & $>0.05$ & 1.07 & 0.03 & $<0.001$ & $\begin{array}{l}3 \text { animals normal } \\
3 \text { animals occasional } \\
\text { fatty change } \\
\text { (<25\% of parenchyma) } \\
\text { All } 7 \text { animals had marked } \\
\text { fatty change } \\
\text { ( }>75 \% \text { of parenchyma) }\end{array}$ \\
\hline
\end{tabular}

*Significance of difference from normal diet group. 
in each of 10 crypts per specimen, and the mean value obtained.

\section{Experiments and results}

As in previous experiments the elemental diet mice grew satisfactor ily and appeared normal and healthy, although the body weight was $5-10 \%$ less than that of normal diet animals. They were strikingly placid in behaviour and at post-mortem examination the livers appeared large and pale, and the caecum was small and did not contair gas. Faecal pellets were tiny and few in number.

In order to confirm that the livers of elemental diet animals were indeed abnormal, measurements of body weight, liver weight, and examination of liver histology were carried out in a group of six normal diet and six elemental diet mice aged 10 weeks. The results, summarised in Table 1 and illustrated in Figs. 1a and b, confirm the reduced body weight, increased liver weight, and the presence of fatty liver in elemental diet animals.

The Sha Sha mice used for the experiments were confirmed to have heavy Giardia infection of the jejunum at post-mortem examination.

\section{EFFECTS OF ELEMENTAL DIET ON SMALL} INTESTINE OF NORMAL MICE

Six normal diet mice and six elemental diet mice were killed at age 3 months and intestines examined by conventional histology and by the microdissection technique. Macroscopically, the elemental diet mice had narrow calibre intestine with clear contents. Conventional histology revealed no difference when normal diet and elemental diet specimens were compared. Studies of epithelial cell kinetics confirmed similar values for villus length, crypt length, and accumulated metaphases per crypt per hour for normal diet and elemental diet animals of the CBA strain (Fig. 2).

EFFECTS OF ELEMENTAL DIET ON SMALL INTESTINE OF Giardia INFECTED MICE

In animals taking a normal diet, chronic Giardia infection is associated with longer crypts and a significantly raised metaphase accumulation rate when compared with the uninfected animals of the CBA strain (MacDonald and Ferguson, 1978). When mice of the Sha Sha strain were given an elemental diet, and studied at age 3 months, it was found that the elemental diet animals had significantly longer crypts and further increment in metaphase accumulation rate to 18.7 metaphases per crypt per hour (Fig. 2). Thus the known effect of giardiasis in accelerating cell production and cell transit rate up the sides of the villi are further enhanced by elemental diet treatment of the animals.

\section{EFFECTS OF ELEMENTAL DIET ON COURSE OF Nippostrongylus brasiliensis INFECTION}

The effects of Nippostrongylus brasiliensis infection on the animals' weight was examined in six normal diet and six elemental diet mice. Each was weighed immediately before the subcutaneous injection of larvae, and daily thereafter for 12 days. The results, shown in Fig. 3, confirm that the group of elemental diet mice weighed significantly less than the normal diet animals before infection. In both groups there was a drop in weight on day 2 post-infection. From the seventh day after infection, the elemental diet animals remained consistently and significantly lighter than the normal diet group and, whereas from day 2 there was a daily increment in normal diet

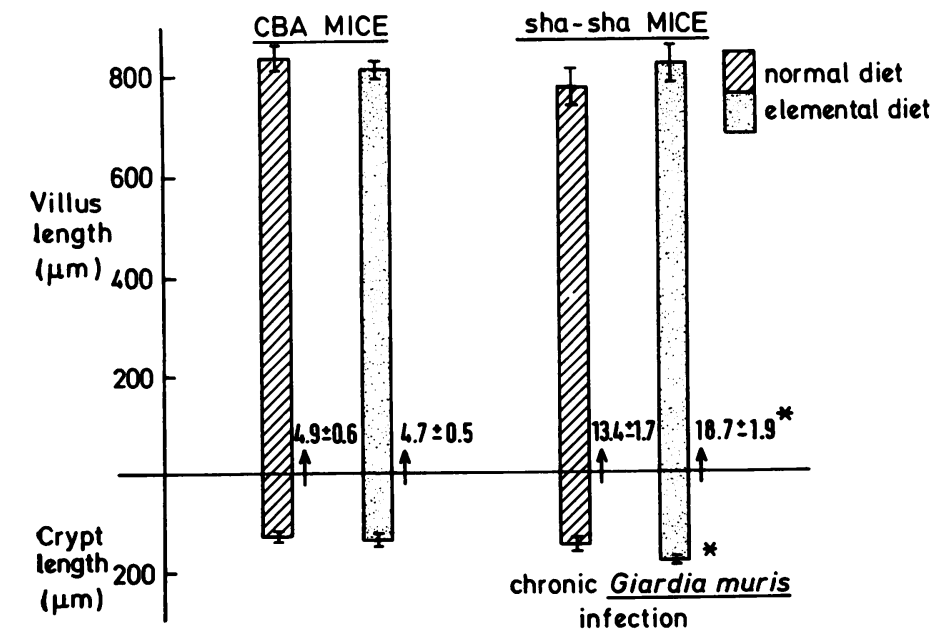

Fig. 2 Intestinal mucosal architecture in normal diet and elemental diet mice of the CBA strain (uninfected) and Sha Sha strain (chronically infected with Giardia muris). At least six mice per group. Values given are mean \pm 1 standard error. The arrow indicates the number of accumulated metaphases per crypt per hour in each experimental group. ${ }^{*} \mathrm{p}<0.01$. 
Fig. 3 Weights (mean + standard error) of normal diet and elemental diet $C B A$ mice, before and for 12 days after infection with 1000 Nippostrongylus brasiliensis larvae.

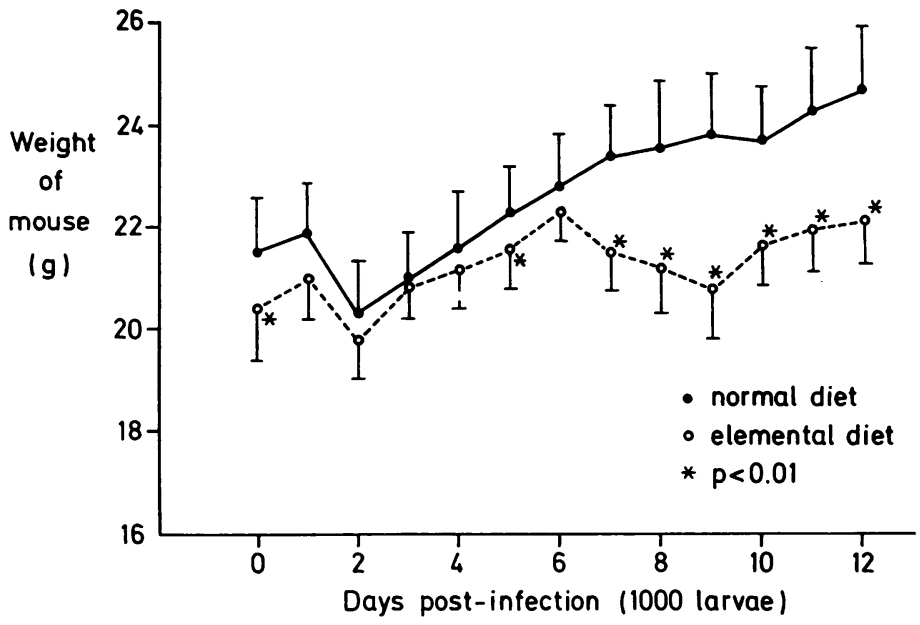

EFFECTS OF ELEMENTAL DIET ON SMALL INTESTINE HISTOLOGY AND ARCHITECTURE IN Nippostrongylus brasiliensis INFECTION

In a preliminary experiment 12 normal diet and 15 elemental diet mice were infected with 1000 larvae and killed at intervals from six to 15 days. Specimens were taken at $10 \mathrm{~cm}$ from the pylorus for conventional histology. In the normal diet animals changes were minor and comprised slightly increased lymphoid cell infiltrate of the lamina propria and villus shortening in a proportion of the animals (Fig. 5a). All four specimens studied from animals killed on day 15 were normal. In the elemental diet mice, the range of severity of pathology was greater. Several animals had very short or absent villi and long crypts and others had less severe abnormalities (Figs. 5b, 5c). Results of subjective grading of the histology of the specimens is shown in Table 1. examined up to day 15 .

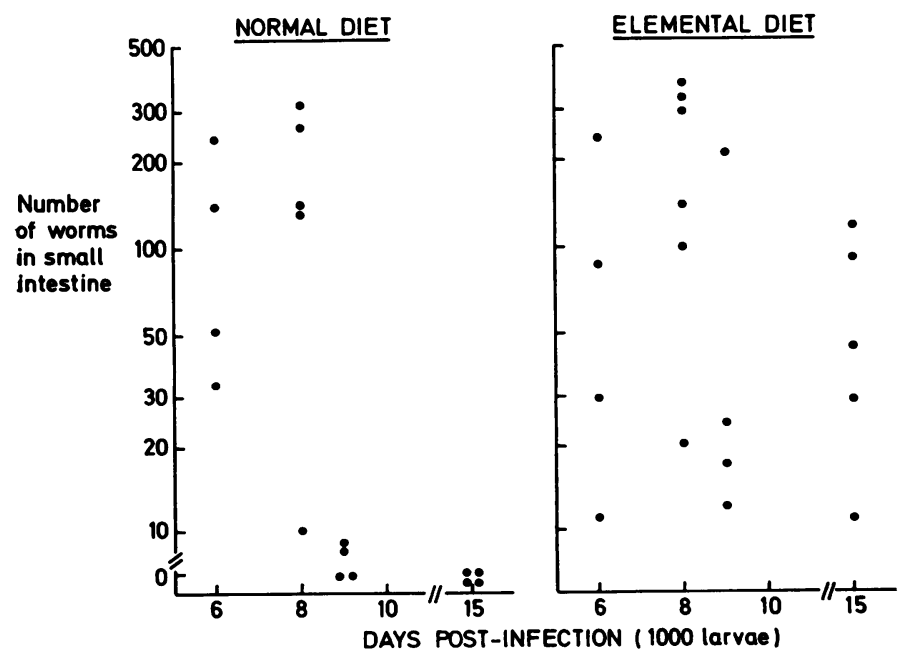

Fig. 4 Worm counts at intervals after Nippostrongylus brasiliensis infection, in mice fed a normal diet and elemental diet. 


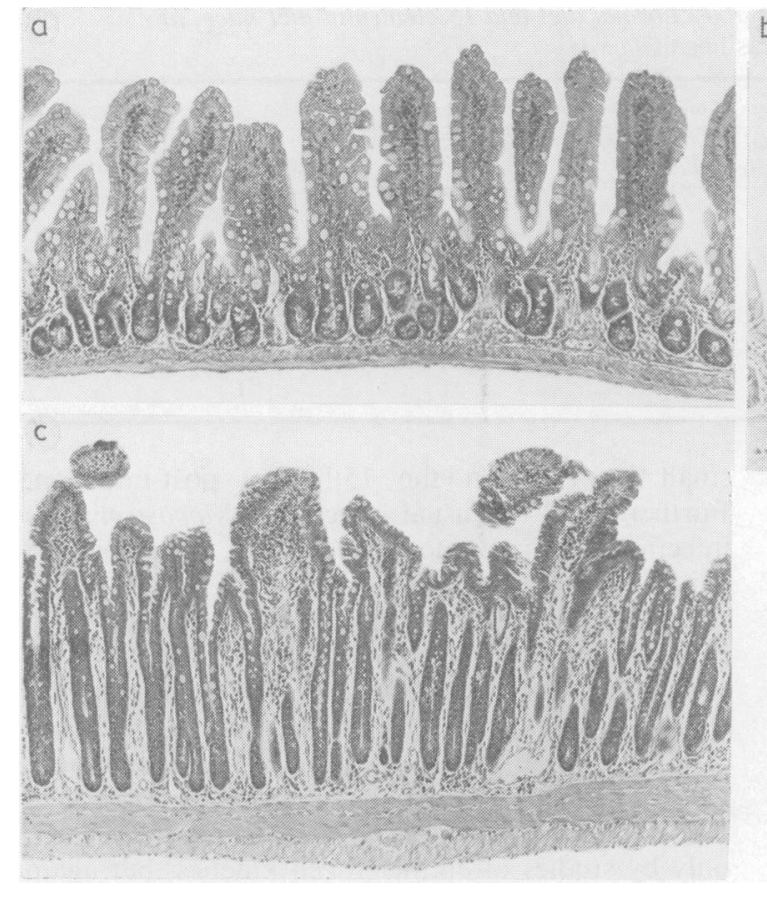

In order to carry out a more detailed investigation at a single time point, of the inter-relating effects of diet and infection on intestinal architecture, the seventh day post-infection was chosen as a suitable

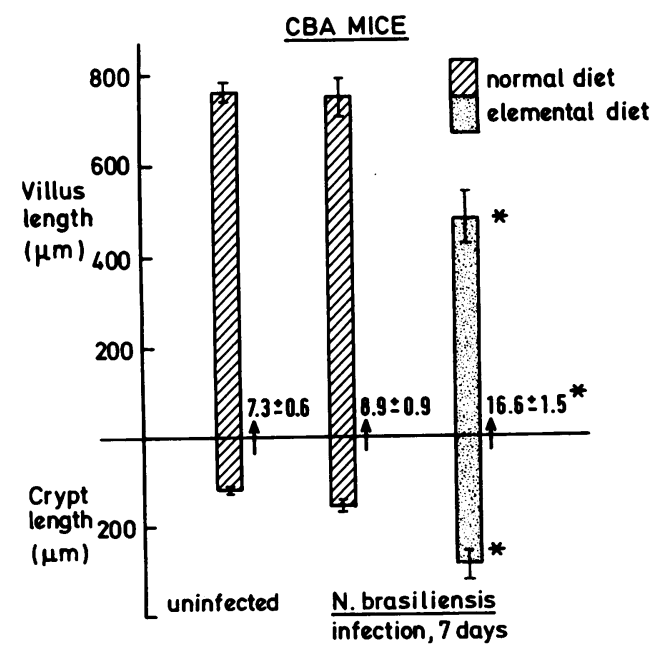

Fig. 6 Intestinal mucosal architecture in normal diet, uninfected mice of the $C B A$ strain, and in normal diet and elemental diet $C B A$ mice on the seventh day after infection with 1000 larvae of Nippostrongylus brasiliensis. Six mice per group. The arrow indicates the number of accumulated metaphases per crypt per hour in each experimental group. ${ }^{*} \mathrm{P}<0.01$.

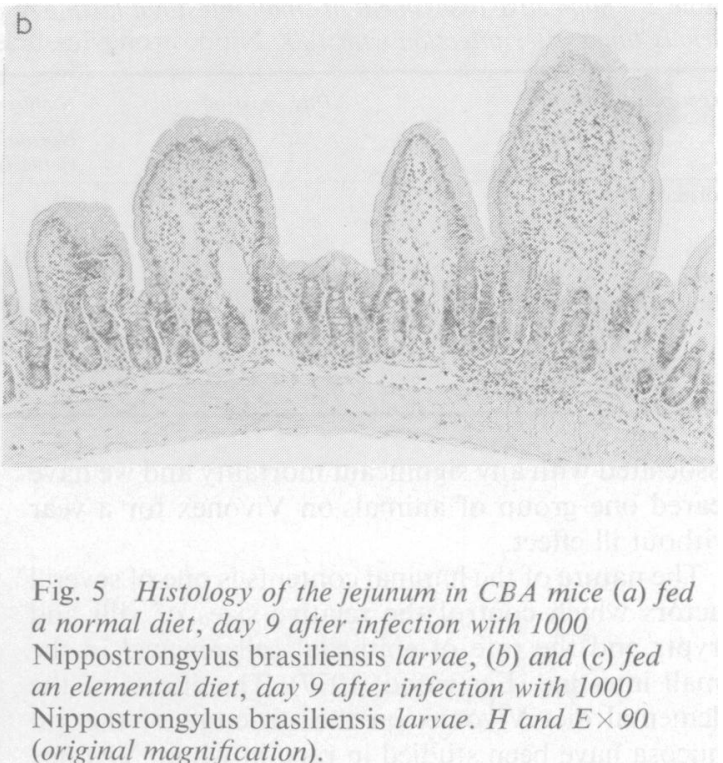

time when both normal diet and elemental diet animals were likely to have similar numbers of worms established in the intestine. Thus measurements of villus and crypt length and of metaphase accumulation rate were carried out in six normal diet infected animals, six elemental diet infected animals, and six normal diet uninfected mice, all of the CBA strain. Results are given in Fig. 6. They show that in normal diet infected animals, the slightly increased crypt length and metaphase accumulation rate were not significantly higher than in controls. However in elemental diet animals there was villus shortening, significantly increased lengthening of crypts, and the metaphase accumulation rate was 16.6 metaphases/ crypt/hour, as compared with 8.9 for the infected, normal diet group.

\section{Discussion}

Elemental, chemically defined diets such as Vivonex are used in the management of a number of gastrointestinal diseases, for they have no residue, are not immunogenic, and can be absorbed across the small intestinal mucosa in the absence of pancreatic and other digestive secretions (Russell, 1975). Although designed for human use, Vivonex appears to be nutritionally adequate for laboratory rodents. We have found that Vivonex reared animals tend to be about $10 \%$ lighter than animals reared on a normal diet, and they have fatty liver but the diet is not 
Table 2 Subjective assessment of small intestinal histology of 12 normal diet and 15 elemental diet mice, at various times after infection with 1000 Nippostrongylus brasiliensis larvae

\begin{tabular}{|c|c|c|c|c|}
\hline \multirow[t]{2}{*}{ Experimental group } & \multirow[t]{2}{*}{ Days post-infection } & \multicolumn{3}{|c|}{ Number of animals with histological grading of: } \\
\hline & & $\begin{array}{l}\text { Normal or } \\
\text { virtually normal }\end{array}$ & $\begin{array}{l}\text { Partial villous } \\
\text { atrophy }\end{array}$ & $\begin{array}{l}\text { Subtotal villous atrophy } \\
\text { (flat surface) }\end{array}$ \\
\hline Normal diet & $\begin{array}{r}6 \\
8 \\
9 \\
15\end{array}$ & $\begin{array}{c}3 \\
\frac{3}{2} \\
4\end{array}$ & $\begin{array}{r}\overline{2} \\
1 \\
-\end{array}$ & $\begin{array}{l}E \\
-\end{array}$ \\
\hline Elemental diet & $\begin{array}{r}6 \\
8 \\
9 \\
15\end{array}$ & $\begin{array}{r}1 \\
1 \\
1 \\
-\end{array}$ & $\begin{array}{l}2 \\
2 \\
2 \\
3\end{array}$ & $\frac{\overline{1}}{\overline{1}}$ \\
\hline
\end{tabular}

associated with any significant mortality and we have reared one group of animals on Vivonex for a year without ill effect.

The nature of the luminal contents is one of several factors which control the relative sizes of villi and crypts and the rate of epithelial cell renewal in the small intestine (Eastwood, 1977). The effects of the elemental diet Vivonex on the structure of the gut mucosa have been studied in rats, in whom Vivonex fed animals have longer villi and shorter crypts than controls (Nelson et al., 1978), suggesting a slower cell proliferation rate; and such animals also have colonic mucosal atrophy (Janne et al., 1977). In these respects, the effects of elemental diet on intestinal epithelial cell kinetics are similar to those of bypass operations, or total parenteral nutrition (Eastwood, 1977; Williamson, 1978). The present series of experiments have been carried out in mice, and results in normal animals indicate that there may be a species difference in this effect of elemental diet on cell turnover. By using a sensitive microdissection technique in addition to conventional histology, we have found that an elemental diet has no effect on the intestinal architecture of normal conventionally reared, parasite free mice.

Although on theoretical grounds the presence of easily absorbed nutrients at the luminal surface of the small intestine might be expected to reduce the amount of damage associated with extrinsic agents, such as parasites, we found that Nippostrongylus brasiliensis infection of elemental diet fed mice produced a more severe clinical illness than the same magnitude of infection in an animal fed normal diet (Ferguson, 1976; Ferguson et al., 1978). We have now shown that these clinical effects are paralleled by increased severity of mucosal abnormality in the small intestine. These aspects have been examined most fully in relation to Nippostrongylus infection, in which the parasite load at different times can be measured. Not only do the animals fed an elemental diet lose weight after infection, but they also have an impaired ability to eliminate the complete parasite load, as illustrated by the presence of worms in the small intestine on the 15th day post-infection. Furthermore, the usual effects of Nippostrongylus infection in mouse intestine-namely, of accelerated epithelial cell turnover-were enhanced by the elemental diet and a further aspect of pathology, villus shortening early in the course of infection, was produced. Thus, rather than the elemental diet protecting against the adverse effect of this helminth infection, paradoxically a more severe enteropathy has resulted. The enhanced enteropathy associated with Giardia muris infection could be demonstrated only by studies of epithelial cell kinetics, but again showed a further increment in epithelial cell turnover rate in the elemental diet fed animals as compared with infected normal diet controls.

We have not yet established the mechanism for this increased mucosal damage. It is conceivable that either the presence of high concentrations of nutrients within the gut lumen, or reduced competition for available nutrients by the gut flora, improves the nutrition of the parasites themselves and thereby increases their virulence. Alternatively, reduced small intestinal motility may render the final stage of expulsion of immune damaged parasites less efficient than normal. A further mechanism to be considered is an alteration in antiparasite immune responses. We have previously examined the effects of elemental diet on the immune status of otherwise normal mice, and, although we found that the animals had normal cell mediated immune capacity, they had an impaired capacity to make antibodies, at least to the antigen used for the experiments, bovine serum albumin (Ferguson et al., 1978). There is now evidence that the thymus dependent immune response contributes to the enteropathy of parasite infections (Ferguson and Jarrett, 1975; Roberts-Thomson and Mitchell, 1978; Manson-Smith et al., 1979). Thus relative enhancement of the cell mediated component of antiparasite immunity, as would be produced in elemental diet animals, will theoretically result in greater tissue damage (Ferguson, 1978). When the humoral component of the immune response is impaired, and when non-specific effector mechanisms 
such as motility are abnormal, such an enhanced local cell mediated immune response may nevertheless be ineffectual as an antiparasite mechanism.

Whatever the reason, we have clearly demonstrated for two intestinal infections of mice that the host parasite relationship is altered by the long-term use of an elemental diet. This results not only in enhanced tissue damage but almost certainly enhanced malabsorption and, in addition, prolongation of the course of infection with the helminth Nippostrongylus brasiliensis. It will be important to establish the mechanisms involved in order to determine if these observations are of clinical relevance to man. For the moment our findings should merely be borne in mind if elemental diets are used in persons potentially infected with helminth or protozoal parasites.

The Vivonex used for these experiments was kindly supplied free of charge by Eaton Laboratories. We acknowledge the skilled technical assistance of the staff of the Animal Unit at the Western General Hospital. This work was supported by grants from the National Fund for Research into Crippling Diseases and the Camilla Samuel Fund.

\section{References}

Eastwood, G. L. (1977). Gastrointestinal epithelial renewal. Gastroenterology, 72, 962-975.

Ferguson, A. (1976). Elemental diet. Effects on immune status and on hypersensitivity reactions in the gut. In Role of Elemental Nutrition, pp. 14-18. Edited by I. D. A. Johnston. M.C.S. Consultants: Tunbridge Wells.

Ferguson, A. (1978). Lymphocytes and cell mediated immunity in the small intestine. (Goulstonian Lecture). In Advanced Medicine, vol. 14, pp. 278-293. Edited by D. J. Weatherall. Pitman Medical: Tunbridge Wells.

Ferguson, A., and Jarrett, E. E. E. (1975). Hypersensitivity reactions in the small intestine. I. Thymus dependence of experimental 'partial villous atrophy'. Gut, 16, 114-117.
Ferguson, A., Paul, G., and MacDonald, T. T. (1978). Immunodeficiency and fatty liver in mice reared on an elemental diet. Arquivos de Gastroenterologia, 15, 11-15.

Janne, P., Carpentier, Y., and Willems, G. (1977). Colonic mucosal atrophy induced by a liquid elemental diet in rats. American Journal of Digestive Diseases, 22, 808-812.

Jarrett, E. E. E., Jarrett, W. F. H., and Urquhart, G. M. (1968). Quantitative studies on the kinetics of establishment and expulsion of intestinal nematode populations in susceptible and immune hosts. Nippostrongylus brasiliensis in the rat. Parasitology, 58, 625-639.

Jennings, F. W., Mulligan, W., and Urquhart, G. M. (1963). Variables in $x$-ray 'inactivation' of Nippostrongylus brasiliensis larvae. Experimental Parasitology, 13, 367-373.

Loehry, C. A., and Creamer, B. (1969). Three-dimensional structure of the rat small intestinal mucosa related to mucosal dynamics. Gut, 10, 112-120.

MacDonald, T. T., and Ferguson, A. (1978). Small intestinal epithelial cell kinetics and protozoal infection in mice. Gastroenterology, 74, 496-500.

Manson-Smith, D. F., Bruce, R. G., and Parrott, D. M. V. (1979). Villous atrophy and expulsion of intestinal trichinella spiralis are mediated by $\mathrm{T}$ cells. Journal of Parasitology. (In press).

Nelson, L. M., Carmichael, H. A., Russell, R. I., and Lee, F. D. (1978). Small-intestinal changes induced by an elemental diet (Vivonex) in normal rats. Clinical Science and Molecular Medicine, 55, 509-511.

Roberts-Thomson, I. C., and Mitchell, G. F. (1978). Giardiasis in mice. 1. Prolonged infections in certain mouse strains and hypothymic (nude) mice. Gastroenterology, 75, 42-46.

Russell, R. I. (1975). Elemental diets. Gut, 16, 68-79.

Symons, L. E. A. (1965). Kinetics of the epithelial cells, and morphology of villi and crypts in the jejunum of the rat infected by the nematode Nippostrongylus brasiliensis. Gastroenterology, 49, 158-168.

Williamson, R. C. N. (1978). Intestinal adaptation. Structural, functional and cytokinetic changes. New England Journal of Medicine, 298, 1393-1402. 